\title{
RESPIRATORY COMPLICATIONS OF INFECTIOUS DISEASES
}

Part of the summer (1960) meeting of the Thoracic Society in Edinburgh was devoted to a short symposium on the respiratory complications of the infectious diseases. As was rightly pointed out in the opening paper, such a title may be misleading, for it seems almost to imply the existence of some prescribed list of such conditions, whereas, of course, the infectious diseases prevalent in any period of time must be seen to depend on the interplay of all those many factors which can influence the hosts, the parasites, and the environment in which they meet. The pattern of infectious diseases in a community must constantly be changing. Because of the effects of immunization and the efficiency of chemotherapy (and probably because of some unexplainable natural changes in epidemic behaviour) the classical infectious diseases of the last generation no longer present the same formidable problems. It is dangerous to assume that infectious disease is, therefore, "conquered" or even perhaps that its totality is diminished.

At the end of last century the rapid advances in the discovery of the bacterial causes of different infections were made possible by the painstaking preliminary work in the field which had done so much to differentiate many of them simply by observation of their clinical course and epidemiological behaviour. So at the present time there is a need to appreciate that the new techniques which enable the virologist to identify new viruses at a bewildering rate will require the support of equally precise observation by a variety of other people.

It is, of course, more difficult with virus infections to relate, on clinical grounds, a particular virus with certain signs and symptoms. The response, for instance, of mucous membrane to cellular damage does not allow much chance of variation, so that different viruses may produce a somewhat similar histological change. G. B. S. Roberts illustrated this well by showing that, for example, measles virus, influenza virus, and the viruses responsible for acute laryngo-tracheobronchitis could all produce a similar histological picture in the upper respiratory tract. Those infections in which there is viraemia often produce a more specific reaction. Measles, for example, gives rise to widespread lesions throughout the lymphatic tissue, so that the histological picture is diagnostic. Chicken-pox may affect such organs as the lungs or liver to give a picture which, if not diagnostic, is only seen in a few other infections. The demonstration of many of these changes, such as inclusion bodies and giant cell formations in the lung parenchyma, has, of course, been rendered much simpler by the fact that previous chemotherapy has removed the bacterial effects and allowed the virus lesion to stand out.

In certain circumstances it may be necessary to use other devices such as those of the epidemiologist or the statistician in suggesting a virus aetiology. It was, therefore, salutary that R. G. Sommerville and P. S. Macfarlane should present evidence that in the calf a virus pneumonitis may be responsible for a chronic obstructive pulmonary lesion in the older animal. A study of the histology of non-tuberculous juvenile bronchiectasis showed many similarities with the calf disease and prompted them to examine a series of cases and controls for virus infection. They advanced strong serological evidence that the original cause of some of these lesions might well be a chronic adenovirus infection.

But, in looking for new virus diseases, we must not forget the old. One of the interesting phenomena, for example, of the past 30 years has been the gradual emergence of poliomyelitis as an epidemic paralysing disease. This change in behaviour is believed to be due to the fact that the improved standards of hygiene have permitted numbers of persons to reach adult life without experiencing the polio virus and acquiring immunity to it. Poliomyelitis thus acquires the merit of a "status symbol "- to use a neologism !

But what is true of polio virus may well be true of other viruses, so that the exposure of the adult to a virus which is of little moment to the child may induce an explosive reaction of much greater severity. J. Stevenson pointed out that when, in 1942, Waring, Neubuerger, and Geever described a case of chicken-pox pneumonitis, they found no mention of it in past records. Since then well over 70 cases have been described, almost always in adults and in many cases leading to death. He suggested indeed that there might be need to take another look at one of the most well-known simple virus infections, namely, herpes simplex, for he had encountered a number of serious sequelae to adult infection in the last few years.

Finally, virus infection of man is often assumed to arise solely from human contact. But man's animal contacts may repay closer study, for not 
only may man suffer from animal virus infection but animals may well act as unknown reservoirs. Ornithosis was the subject of the last paper in which Professor Anderson analysed a series of 21 cases. It is generally believed that a history of contact with birds-usually parrots, budgerigars, or pigeons-is invariable. It was, therefore, surprising to hear that in many proven cases a very careful survey revealed no association. The seasonal distribution, even in this small series, was also interesting, for 15 of the 21 cases occurred in the first six months of the year. The suggestion was advanced that this was perhaps due to changes in the behaviour or the health of birds during mating, nesting, and egg-laying rather than to any variation in human resistance.

The symposium undoubtedly emphasized that, if chemotherapy has sterilized the bacteria that produced so many of the infections, it certainly has not sterilized the subject. Man is often so fearful of the new that he fails to recognize the old in a new guise. In bacteriology that nuisance of the past which produced pimples, furuncles, or occasional boils is now the redoubtable pathogen which can close a maternity unit or vitiate the work of the most skilled surgeon. The new viruses demand close study, no doubt, but even measles, chicken-pox, and mumps may carry risks to the adult who has failed to gain his immunity in the social paradise of his childhood.

Thomas ANDERSON.

\section{REFERENCE}

Waring, J. J., Neubuerger, K. T., and Geever, E. F. (1942). Arch. intern. Med., 69, 384. 